\title{
WAY OF CONNECTION OF A THREE-PHASE MOTOR TO A SINGLE-PHASE NETWORK VIA RESONANCE EFFECT \\ Zharilkassin Iskakov ${ }^{1}$, Vladimir Kossov ${ }^{2}$
}

\begin{abstract}
In this paper, we propose a method to connect a three-phase motor, with windings connected by a star and a phaseshifting capacitor as the third contact, to a single-phase network, with efficient use of electrical energy due to compensation of reactive power and due to effective distribution of the voltage in front of the motor's oscillating circuit. A resonance phenomenon in an oscillating circuit of the motor is used to compensate for reactive power, i.e. to increase the active power coefficient to the maximum value. A capacitor bank in front of the circuit is used to effectively distribute the voltage at the input of the motor circuit in order to increase the motor voltage from the mains value of $220 \mathrm{~V}$ to the nominal value of a three-phase motor of $380 \mathrm{~V}$. A special installation was created for experimental studies. The results of experimental studies, theoretical calculations of the electrical circuit of the installation, as well as the voltage vector diagram of the motor circuit show that the case when voltages on the motor are $\mathrm{U}=380 \mathrm{~B}\left(\mathrm{U}_{\mathrm{L}}=\mathrm{U}_{\mathrm{C} 5}=325.4 \mathrm{~B}\right)$ and $\mathrm{U}=392 \mathrm{~B}\left(\mathrm{U}_{\mathrm{L}}=\mathrm{U}_{\mathrm{C} 5}=375.6 \mathrm{~B}\right)$ most closely corresponds to the resonant state of the motor oscillating circuit. The proposed method was introduced into the educational process as a laboratory work for students of technical specialties of the Almaty University of Energy and Communications, and can be used by designers, inventors, scientists and specialists interested in similar issues to create devices that connect a three-phase star-connected motor to a single-phase network.
\end{abstract}

UDC Classification: $537.6 / 8$, 621.3, DOI: $10.12955 /$ cbup.v7.1475

Keyword: three-phase motor, reactive power, resonance effect, power compensation, capacitor bank.

\section{Introduction}

Three-phase asynchronous motors are commonly used in industry and households. Such motors are the most common, and the operation of the majority of motor-powered devices is based just on such motors. Ways to create sufficient torque include connection to the phase-shifting capacitor as the third contact, and other methods, which are offered by the service companies "Master of Cold" (2017), "Tool-Land" (2017) and the channel "Zen. yandex.ru" (2018). A three-phase motor operating in a single-phase network has practically the same rotational rate as one in a three-phase network. However, such a connection significantly reduces asynchronous motor power. This is due to a decrease in voltage between phases from $380 \mathrm{~V}$ to $220 \mathrm{~V}$ and is due to insufficient power drawn from the single-phase network. On the downside, on average, each three-phase motor connected to a singlephase network can lose up to 30 - 50 percent of its own power (Obinstrumente.ru, 2018).

This paper proposes a method to connect a three-phase motor star-connected to a single-phase network, with the electrical energy saving on account of reactive power compensation and voltage increase from $220 \mathrm{~V}$ to $380 \mathrm{~V}$. Most modern consumers of sinusoidal electric power are presented by inductive loads with currents that lag in phase behind the supply source voltage. The active power of such consumers at a given current and voltage values still depends on the power factor $\cos \varphi$.

A near-resonance effect was used to compensate for the reactive power, and a capacitor bank in front of the three-phase motor circuit was used to save electrical energy. In a motor circuit, the load (winding) is mainly inductive. It is compensated with capacitances. This helps to increase $\cos \varphi$ to acceptable values of 0.7 to 0.9 . The economic effect of the introduction of reactive power compensation devices ranges from 12 to $50 \%$ (Electrik.info, 2018).

\section{Research Methodology}

The installation for connecting a three-phase motor to a single-phase network (Fig. 1) consists of amperemeters $A$ and $A_{1}$, a voltmeter $V$, capacitances $C, C_{5}, C_{6}$ and a three-phase motor, electric circuit of which is shown in Fig. 2. DT-830D type multimeters are used as electrical measuring instruments; the measurement limit is $10 \mathrm{~A}$ in the ammeter mode; the measurement limit is $600 \mathrm{~V}$ in the voltmeter mode. 5AY 80A4 U2 type three-phase induction motor has nominal power of $1.1 \mathrm{~kW}$, rotation speed of $1400 \mathrm{of} \mathrm{r} / \mathrm{min}$, efficiency coefficient of $78.5 \%, \cos \varphi=0.74$. Instruments are certified by the electric measuring instruments standardization and certifications center.

\footnotetext{
${ }^{1}$ Almaty University of Power Energy and Communications, Institute of Mechanics and Machine Science, Almaty, Kazakhstan, iskakov53@mail.ru

${ }^{2}$ Almaty University of Power Energy and Communications, Almaty, Kazakhstan, kaftf@mail.ru
} 

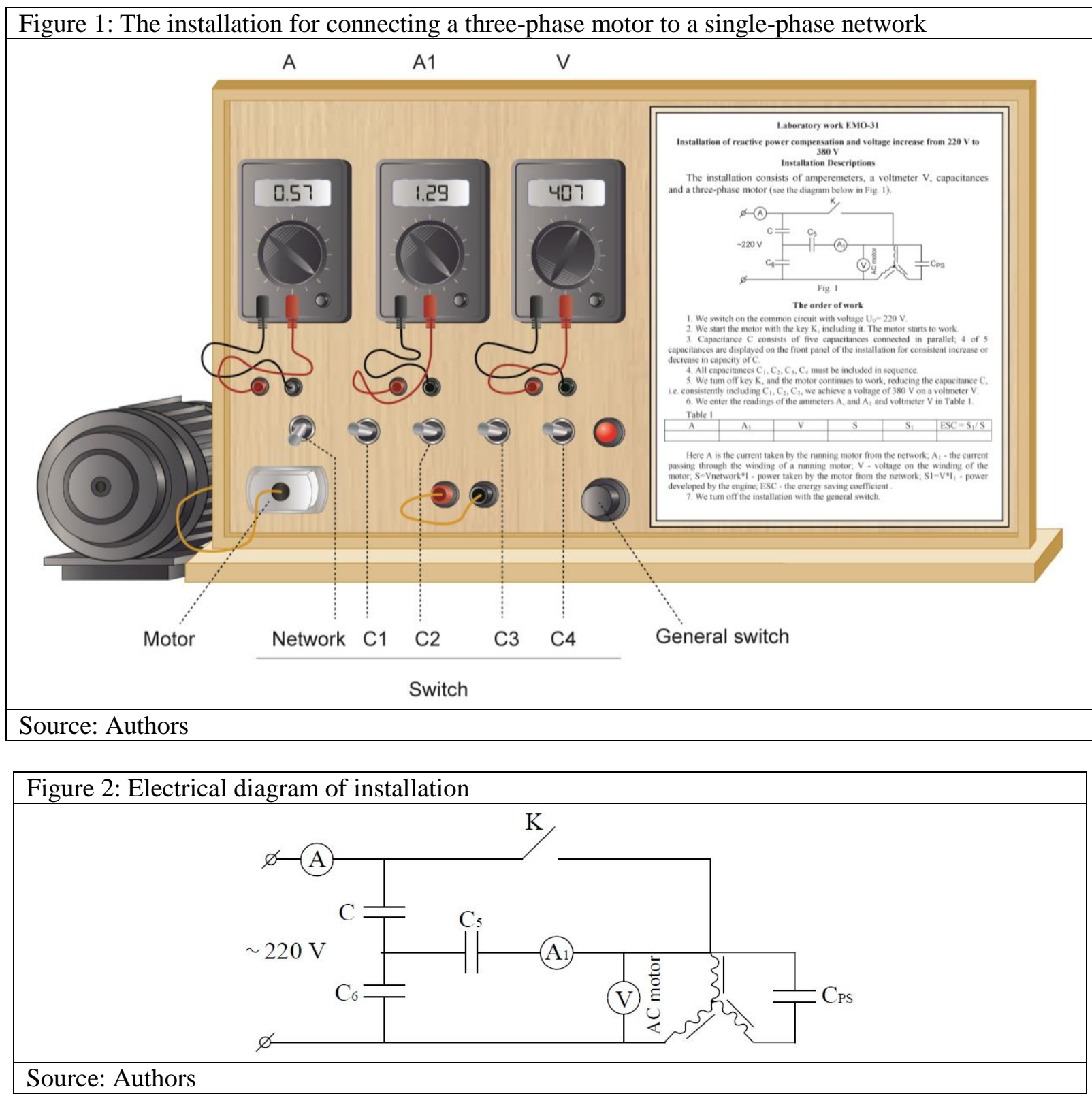

In the system, three windings of a three-phase motor star-connected to one common point, are connected to a single-phase circuit in the following way. The second ends of the first and second windings are connected to each other through a phase-shift capacitance Cps $=5 \mu F$ "Tool-Land" (2017), from the other side the second end of the first winding is connected simultaneously to the key path $K$ and the second end of the third winding is connected to the internal circuit of a single-phase circuit. When the $C$ capacitor is off and the $K$ key is turned on, a mains voltage of $220 \mathrm{~V}$ is applied to the second ends of the first and third windings and together with the phase shifting capacitor $C p s$ provide voltage drops between adjacent phases equal to $220 \mathrm{~V}$ with phase shifts equal to $120^{0}$ "ToolLand "(2017). If we consider that usually the voltage between the phases of the motor windings in a three-phase circuit is $380 \mathrm{~V}$, then when a three-phase motor is connected to a single-phase network, a significant reduction in the total power consumed by the motor due to a decrease in the voltage between phases from $380 \mathrm{~V}$ to $220 \mathrm{~V}$ is understandable. It is necessary to increase the voltage from $220 \mathrm{~V}$ to $380 \mathrm{~V}$ and higher values which is possible by creating a resonance condition in the motor circuit with an active resistance $R$, windings inductance $L$ and capacity $C_{5}$, to eliminate deficiency in total power consumed by the motor and to increase the total power more. Under conditions of resonance, the voltage applied to the motor considerably exceeds the mains voltage, the reactive power at the inductive impedance of the motor winding is compensated with the reactive power at 
capacitance of the capacitor $C_{5}$. Then the motor power coefficient approaches its limit value and the power supplied from the mains to the motor circuit will be approximately equal to the active power at the active resistance of the motor windings. Therefore, the purpose of this study is to design a system and its electrical circuit ensuring the achievement of resonance in the motor circuit with a voltage at the ends of the neighboring windings equal to $380 \mathrm{~V}$ or more, to increase the total power consumed by the motor significantly higher than the mains power. Experimental and theoretical studies were carried out to implement this.

\section{Results and its Discussion}

An experimental investigation was carried to the following procedure. Ammeter $A$ measures the current in the mains, $A_{1}$ measures the current in the motor, $V$ measures the motor neighboring windings voltage. Capacitance $C$ consists of five capacitances connected in parallel; 4 of 5 capacitances are displayed on the front panel of the installation. The work is performed in the following order. Switch on the common circuit with voltage $U_{0}=220 \mathrm{~V}$. When switch on the key $K$, obtaining $U_{0}=220 \mathrm{~V}, I=0.48 \mathrm{~A}, I_{1}=0.29 \mathrm{~A}$. Power in the mains is $S_{1}=U_{0} I$, full rotor power is $S_{2}=U I_{1}$. All capacitances $C$ must be included in sequence; $C_{6}=10 \mu F$. Turn off key $K$, and the motor continues to work. While reducing the capacitance, change the voltage $U_{2}$ on the capacitor $C_{6}$.

With an increase in the capacitance of the capacitor $C_{6}$, its capacitance $X_{C}$ decreases and, accordingly, the voltage $U_{1}$ is dropping on it, due to this the voltage $U_{2}$ on the capacitor $C_{6}$ increases, i.e. the voltage applied to the oscillating circuit of the motor and the motor voltage $U$ also increase. The current strength in the motor circuit $I_{1}$ is greater than the current strength of the mains $I$, and it also increases. The voltage $U$ becomes significantly greater than $U_{2}$ and, accordingly, the voltage of the mains $U_{0}$ for the account of the reactive component $U$ on the inductive resistance of the motor windings $U_{L}$, which at resonance is compensated with voltage $U_{C 5}$ on the capacitance $X_{C 5}$ of the capacitor $C_{5}$.

Enter measurement results in Table 1.

\begin{tabular}{|c|c|c|c|c|c|}
\hline \multicolumn{6}{|c|}{ Table 1: Experimental Data } \\
\hline $\mathrm{C}[\mu \mathrm{F}]$ & 7.5 & 8.5 & 9.5 & 10.5 & 11.5 \\
\hline $\mathrm{U}_{2}[\mathrm{~V}]$ & 94.6 & 101.2 & 107.8 & 112.2 & 117.7 \\
\hline $\mathbf{U}_{2} / \mathbf{U}_{0}$ & 0.43 & 0.46 & 0.49 & 0.51 & 0.53 \\
\hline $\mathbf{I}[\mathbf{A}]$ & 0.65 & 0.63 & 0.62 & 0.61 & 0.59 \\
\hline $\mathbf{I}_{1}[\mathbf{A}]$ & 0.88 & 1.03 & 1.12 & 1.19 & 1.26 \\
\hline $\mathbf{U}[\mathbf{V}]$ & 346 & 370 & 380 & 392 & 400 \\
\hline $\mathbf{S}_{\mathbf{1}}[\mathbf{V} * \mathbf{A}]$ & 143 & 138.6 & 136.4 & 134.2 & 129.8 \\
\hline $\mathbf{S}_{\mathbf{2}}[\mathbf{V} * \mathbf{A}]$ & 304.5 & 381.1 & 425.6 & 466.5 & 504 \\
\hline $\mathbf{S}_{2} / \mathbf{S}_{1}$ & 2.13 & 2.75 & 3.12 & 3.48 & 3.88 \\
\hline
\end{tabular}

The energy saving coefficient (ESC) is characterized by $S_{2} / S_{1}$. With rated linear voltage on the motor, $U=380 V$ (see Table 1), ESC is 3.12. The efficiency coefficient of the motor circuit is $P_{2} / P_{1} \approx 0.89$.

We carry out the substantiation of the above assumption and the results of experimental investigations. Power dependence on $\cos \varphi$ must be considered when designing an $\mathrm{AC}$ power transmission circuit. If the supplied loads have a large reactance $X=X_{L}-X_{C}$, then $\cos \varphi$ can be noticeably less than one. In these cases, to transfer the required power to the consumer (with such mains voltage), $I$ should be increased, which leads to an increase in useless energy losses in the supply lines. Therefore, attempts must be always made to distribute the load, inductance and capacitance so that $\cos \varphi$ is as close to one as possible. To do this, it is enough to make the reactance $X$ as small as possible, i.e. ensure 
equality of inductive and capacitive impedances: $X_{L}=X_{C}$, i.e. to create a condition in the circuit close to resonance (Irodov, 2013).

Additionally, inductance voltage

$$
U_{L r}=\omega L I_{1}
$$

and capacitance voltage

$$
U_{C r}=\frac{1}{\omega C_{5}} I_{1}
$$

are equal to each other:

$$
U_{L r}=U_{C 5 r}=\sqrt{\frac{L}{C_{5}}} I_{1}=\frac{1}{R} \sqrt{\frac{L}{C_{5}}} U_{2} .
$$

If the characteristic wave impedance of the circuit is greater than its active resistance (of motor winding) (Atabekov, 2009)

$$
\rho=\sqrt{\frac{L}{C_{5}}} \succ R,
$$

then inductance voltage $U_{L r}$ and capacitance voltage $U_{C r}$ will exceed the voltage applied to the motor circuit $U_{2}=U_{C_{6}}$ (Savelyev, 2012):

$$
U_{L r}=U_{C 5 r} \succ U_{2}=U_{C_{6}} \cdot
$$

Reactance of a motor circuit containing a winding inductance $L$ and capacitance $C_{5}$ is proportional to the difference of the effectual values of the power stored in the magnetic and electric fields (Atabekov, 2009)

$$
X=\frac{4 \pi}{I^{2}}\left(P_{L}-P_{C}\right)
$$

The condition of resonance ( $X=0$ ) corresponds to the equality

$$
P_{L}-P_{C}=0 \text {. }
$$

The quality of inductance $L$ of the motor winding $Q_{L}=\omega L / R$ and capacitance $C_{5}$ of the capacitor $Q_{C}=\omega C_{5} R$ can be expressed through the maximum power $P_{L m}$ that periodically stores inductance $L$ and the maximum power $P_{C m}$ that periodically stores capacitance $C_{5}$, respectively.

$$
\begin{aligned}
& Q_{L}=2 \pi \frac{P_{L \max }}{P}, \\
& Q_{C}=2 \pi \frac{P_{C \max }}{P} .
\end{aligned}
$$

Where, $P$ is the active power consumed in the motor winding resistances $R$ at the amplitude of current $I_{m}$ or at the amplitude of capacitance voltage $U_{C 5 m}$.

On the other hand, the quality of the motor circuit is as follows:

$$
Q=\frac{\rho}{R} \text {. }
$$

Comparing two expressions (8) and (9) of the circuit quality, we can say that the greater the characteristic wave impedance $\rho$ of the motor circuit, as compared to the active resistance of the windings $R$, the greater the maximum power $P_{L m}$ that periodically stores inductance $L$ or maximum 
power $P_{C m}$ that periodically stores capacity $C_{5}$ compared to the active power consumed in the motor windings $P$, i.e.

$$
P_{L m} \succ P, P_{C m} \succ P
$$

The total power of the oscillating circuit of the motor is

$$
S=\sqrt{P^{2}+\left(P_{L}-P_{C}\right)^{2}} .
$$

In the case of resonance, taking into account (7), we obtain

$$
S=P \text {. }
$$

Total power applied to the motor is

$$
S_{2}=\sqrt{P^{2}+P_{L}^{2}}
$$

If we take into account the experimental results of Table 1: $I_{1} \succ I, U_{2} \succ U_{0}$, and that mains power $S_{1}$ is practically active (12), then taking into account inequalities (10), we can be sure that

$$
S_{2} \succ S_{1}
$$

or power saving coefficient

$$
S_{2} / S_{1} \succ 1
$$

For the theoretical calculation of the electrical circuit in Figure 2, we use the symbolic (complex) method (Bessonov, 1996; Bondarenko, 2004). Network voltage $\dot{U}_{0}$ according to complex Kirchhoff's second law is

$$
\dot{U}_{0}=\dot{I} \dot{X}_{C}+\dot{I}_{r}=\dot{I}\left\{\frac{R}{1+\left(\omega C_{6} R\right)^{2}}-j\left[\frac{\omega C_{6} R^{2}}{1+\left(\omega C_{6} R\right)^{2}}+\frac{1}{\omega C_{5}}\right]\right\} .
$$

Where $\dot{X}_{C}=-j \frac{1}{\omega C}$ is capacitive resistance of capacitor banks;

$\dot{Z}_{r}=\frac{1 / R}{(1 / R)^{2}+\left(\omega C_{6}\right)^{2}}-j \frac{\omega C_{6}}{(1 / R)^{2}+\left(\omega C_{6}\right)^{2}}$ is impedance of the resonant circuit.

Hence, the network current $\dot{I}$ according to Ohm's law in an integrated form is as follows.

$$
\dot{I}=\frac{\dot{U}_{0}}{\frac{R}{1+\left(\omega C_{6} R\right)^{2}}-j\left[\frac{\omega C_{6} R^{2}}{1+\left(\omega C_{6} R\right)^{2}}+\frac{1}{\omega C_{5}}\right]} .
$$

The full circuit impedance is as follows

$$
\dot{Z}=\frac{R}{1+\left(\omega C_{6} R\right)^{2}}-j\left[\frac{\omega C_{6} R^{2}}{1+\left(\omega C_{6} R\right)^{2}}+\frac{1}{\omega C_{5}}\right] .
$$

Its module is as follows

$$
Z=\sqrt{\left[\frac{R}{1+\left(\omega C_{6} R\right)^{2}}\right]^{2}+\left[\frac{\omega C_{6} R^{2}}{1+\left(\omega C_{6} R\right)^{2}}+\frac{1}{\omega C_{5}}\right]^{2}}
$$

Argument $\varphi$ of full circuit impedance can be determined by the formula

$$
\tan \varphi=\frac{\omega C_{6} R+X_{C 5}\left[1+\left(\omega C_{6} R\right)^{2}\right]}{R} .
$$


Then, the complex impedance can be represented as follows.

$$
\dot{Z}=Z e^{-j \varphi} \text {. }
$$

The mains current is as follows.

$$
\dot{I}=\frac{U_{0} e^{j \omega t}}{Z e^{-j \varphi}}=\frac{U_{0}}{Z} e^{j(\omega t+\varphi)}=I e^{j(\omega t+\varphi)} .
$$

According to this formula, we can see that the mains current is ahead of the mains voltage in phase, which means the predominance of capacitive resistance of the circuit. This is explained by the fact that in the case of the motor circuit resonance, the inductive resistance $X_{L}$ of the windings is compensated by the capacitance resistance of the circuit $X_{C 5}: X_{L}-X_{C 5}=0$ and only the active resistance of the windings $R$ and the prevailing capacitances $X_{C}, X_{C 6}$ of the capacitors $C$ and $C_{6}$ will practically act in the circuit.

On the other hand, according to the Kirchhoff's first law, the mains current is equal to the sum of currents in the branches:

$$
\dot{I}=\dot{I}_{1}+\dot{I}_{2} .
$$

Table 2 presents some results of theoretical calculations based on the results of experimental work. Here the voltage $U_{1}$ on distribution capacitance $X_{C}=\frac{1}{2 \pi f C}$ is calculated by the formula

$$
U_{1}=I \cdot X_{C},
$$

active resistance of motor windings by expression

$$
R=\frac{U_{2}}{I_{1}}
$$

Voltage $U_{L}$ on inductive resistance $X_{L}$ of motor windings or voltage $U_{C 5}$ on capacitance $X_{C 5}$ of the oscillatory circuit are found according to the formula

$$
U_{L}=U_{C 5}=\sqrt{U^{2}-U_{2}^{2}} .
$$

Reactive resistances $X_{L}$ and $X_{C 5}$ are calculated by the formula

$$
X_{L}=X_{C 5}=\frac{U_{L}}{I_{1}}=\frac{U_{C 5}}{I_{1}} .
$$

Calculations of inductance $L$, capacity $C_{5}$ of the oscillatory circuit are found according to the formula

$$
L=\frac{X_{L}}{2 \pi f}, C_{5}=\frac{1}{2 \pi f X_{C 5}} .
$$

Wave resistance $\rho$ of the oscillatory circuit is found by the formula (4).

Table 2: The results of theoretical calculations
\begin{tabular}{|c|c|c|c|c|c|c|}
\hline $\mathbf{U}_{\mathbf{1}}[\mathbf{~ V ]}$ & $\mathbf{U}_{\mathbf{L}}=\mathbf{U}_{\mathbf{C 5}}[\mathbf{V}]$ & $\mathbf{R}[\mathbf{O}]$ & $\mathbf{X}_{\mathbf{L}}=\mathbf{X}_{\mathbf{C 5}}[\mathbf{O}]$ & $\mathbf{L}[\mathbf{H}]$ & $\mathbf{C}_{\mathbf{5}}[\boldsymbol{\mu} \mathbf{F}]$ & $\boldsymbol{\rho}[\mathbf{O}]$ \\
\hline 276 & 333 & 107.5 & 378.2 & 1.20 & 8.42 & 377.5 \\
\hline 236 & 356 & 98.3 & 345.5 & 1.10 & 9.22 & 345.4 \\
\hline 208 & 364 & 96.3 & 325.4 & 1.04 & 9.79 & 325.9 \\
\hline 185 & 376 & 94.3 & 315.6 & 1.01 & 10.10 & 316.2 \\
\hline 163 & 382 & 93.4 & 303.4 & 0.97 & 10.50 & 303.9 \\
\hline
\end{tabular}

Source: Authors

We can observe from Table 2 that $\rho \succ R$. 
Let's get a vector diagram of voltages (Fig.3) according to the data of Tables 1 and 2 using the following method. According to the vector sum $\dot{U}_{0}=\dot{U}_{1}+\dot{U}_{2}$, we construct the voltage triangle $U_{0}, U_{1}$ and $U_{2}$. Under resonance conditions, the voltage $U_{2}$ is equal to $U_{R}$, i.e. $U_{2}=U_{R}$, and the vectors $\dot{U}_{L}$ and $\dot{U}_{C 5}$ are equal in value and perpendicular to the vector $\dot{U}_{R}$.

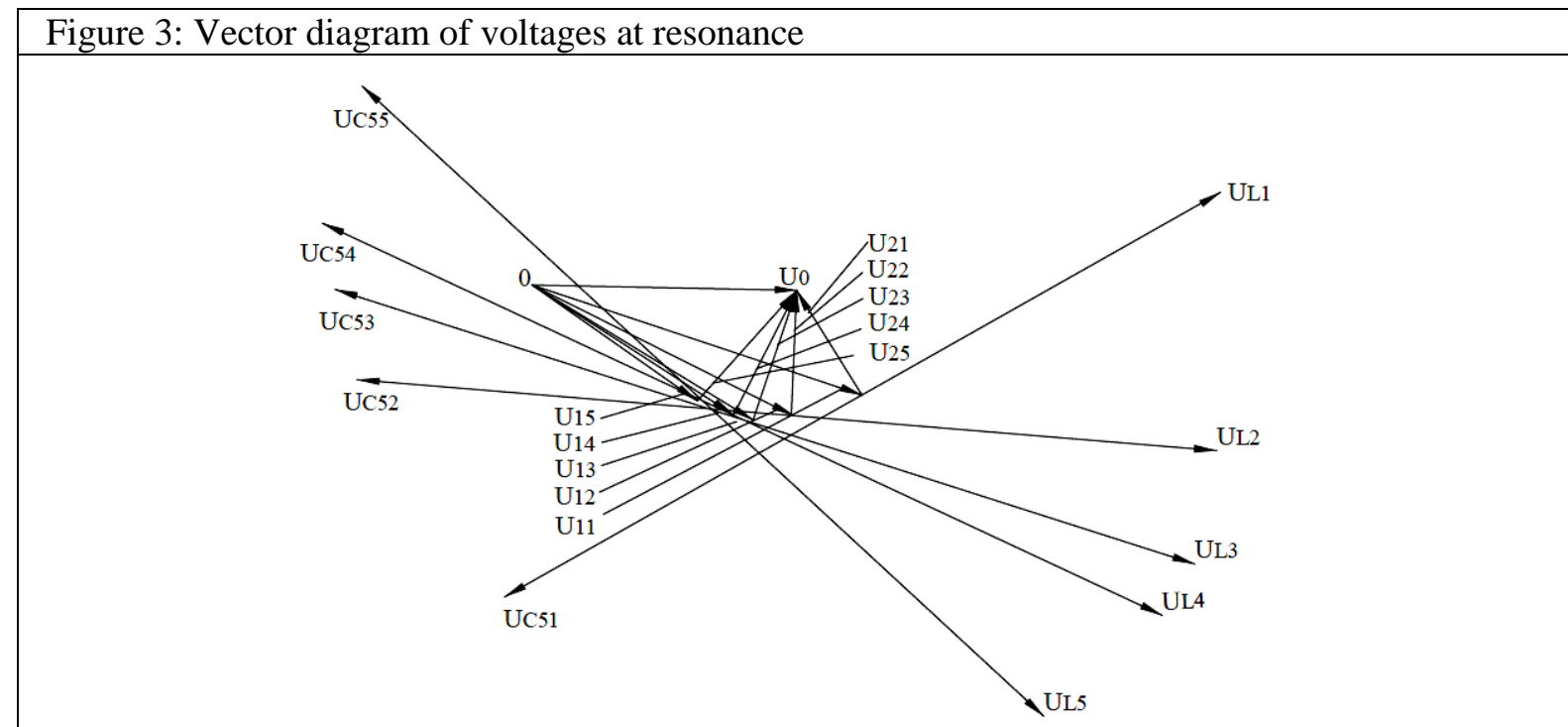

Source: Authors

We can observe from Figure 3 that in the cases with the voltages $U=380 \mathrm{~V}\left(U_{L}=U_{C 5}=325.4 \mathrm{~V}\right)$ and $U=392 \mathrm{~V}\left(U_{L}=U_{C 5}=375.6 \mathrm{~V}\right)$ the vector of voltage $\dot{U}_{1}$ on the capacitance $X_{C}$ and the vector of voltage $\dot{U}_{2}=\dot{U}_{R}$ on the active resistance $R$ of the motor windings is practically mutually perpendicular, which should be at the resonance, and the direction of the values of voltages $U_{L 3}$ and $U_{L 4}, U_{C 3}$ and $U_{C 4}$ proved to be mutually close in comparison with the directions of other voltages values. The power savings and efficiency coefficients of the motor circuit are $\left(S_{2} / S_{1}\right)_{3}=3.12 ;\left(P_{2} / P_{1}\right)_{3} \approx 0.89$ and $\left(S_{2} / S_{1}\right)_{4}=3.48 ;\left(P_{2} / P_{1}\right)_{4} \approx 0.99$, respectively. The values of efficiency coefficient are very close to one. This means that the loss of mains power in the motor circuit is insignificant at resonance. Therefore, the theoretical justification and calculation formulas (4), (24) - (28) are most appropriate for these cases of the resonant state of the motor circuit.

\section{Conclusion}

An experimental setup was created, and a method was proposed to connect a three-phase motor with the star-connected windings and a third contact, a phase-shifting capacitor, to a single-phase network with the effect of electrical energy saving for the account of reactive power compensation and voltage increase from $220 \mathrm{~V}$ to $380 \mathrm{~V}$. A near-resonance phenomenon is used to compensate for reactive power, and a capacitor bank with adjustable capacitance is used in front of a three-phase motor's circuit for efficient use of electrical energy. Experimental studies, theoretical calculations of the electrical circuit of the installation and the justification of their results were carried out. According to the study results, the voltage diagram of the motor circuit was built. It is revealed that the case with voltages on the motor $U=380 \mathrm{~V}\left(U_{L}=U_{C 5}=325,4 \mathrm{~V}\right)$ and $U=392 \mathrm{~V}\left(U_{L}=U_{C S}=375.6 \mathrm{~V}\right)$ is the closest to the resonant state of the motor circuit. In these cases, the energy saving and efficiency coefficients of the motor circuit are $\left(S_{2} / S_{1}\right)_{3}=3.12 ;\left(P_{2} / P_{1}\right)_{3}=0.89$ and $\left(S_{2} / S_{1}\right)_{4}=3.48 ;\left(P_{2} / P_{1}\right)_{4}=0.99$, respectively. The loss of mains power decreases from $11 \%$ to $1 \%$ in the motor circuit. The proposed method to connect a three-phase motor star-connected to single-phase network was introduced into the educational process as a laboratory work for students of technical specialties of the Almaty University of Energy and Communications, and it can be used in electric machine industry to create single-phase induction motors and by designers, inventors and scientists interested in similar issues. 


\section{References}

Atabekov, G.I. (2009). Theoretical foundations of electrical engineering. St. Petersburg, Russia: Lan.

Bessonov, L.A. (1996). Theoretical foundations of electrical engineering. Electrical circuits. Moscow, M: High School.

Bondarenko, V.V. (2004). Fundamentals of circuits. Section 1: Textbook. SPb: Saint Petersburg State University of Cinema and Television.

Connection diagram; selection and calculation of the starting capacitor (2017). Retrieved from https://masterxoloda.ru/1/shema-podklyucheniya-i-raschyot-puskovogo-kondensatora

Connection of a three-phase motor to a single-phase network (2017). Retrieved from http://tool-land.ru/podklyuchenietrekhfaznogo-dvigatelya.php

Independent connection of a three-phase motor to a single-phase network is difficult, but feasible (2018). Retrieved from http://obinstrumente.ru/elektronika/podklyuchenie-trexfaznogo-dvigatelya.html

Irodov, I.E. (2013). Electromagnetism: Basic Laws. Almaty: Association of the Republic of Kazakhstan.

Savelyev, I.V. (2012). The course of general physics (Vol 2). Electricity and magnetism, optics. Moscow, Russia: KnoRus.

Three-phase motor to single phase: 7 available methods (2018). Retrieved from

https://zen.yandex.ru/media/housediz/trehfaznyi-dvigatel-v-odnofaznuiu-set-7-dostupnyh-sposobov-

5 abd15cddb0cd906818b41a2

What is reactive power and how to deal with it - Electrik.info (2018). Retrieved from http://electrik.info/main/school/333chto-takoe-reaktivnaya-moschnost-i-kak-s-ney-borotsya.html 